\title{
The effect of changes in visibility and price on fruit purchasing at a university cafeteria in Lima, Peru
}

\author{
María Kathia Cárdenas ${ }^{1, *}$, Catherine P Benziger ${ }^{2}$, Timesh D Pillay ${ }^{3}$ and J Jaime Miranda ${ }^{1,4}$ \\ ${ }^{1}$ CRONICAS Center of Excellence in Chronic Diseases, Universidad Peruana Cayetano Heredia, Av. Armendariz \\ 497, Miraflores, Lima-18, Peru: ${ }^{2}$ Department of Cardiology, University of Washington, Seattle, WA, USA: ${ }^{3}$ Medical \\ School, University College London, London, UK: ${ }^{4}$ Department of Medicine, School of Medicine, Universidad Peruana \\ Cayetano Heredia, Lima, Peru
}

Submitted 24 January 2014: Final revision received 1 October 2014: Accepted 23 October 2014: First published online 1 December 2014

\begin{abstract}
Objective: To determine the effect of increasing fruit visibility, adding information and lowering price on fruit purchasing at a university cafeteria in Lima, Peru.

Design: Quasi-experimental pilot study of a three-phase stepped intervention. In Phase 1, fruit was displayed $>3 \mathrm{~m}$ from the point of purchase with no additional information. Phase 2 consisted in displaying the fruit near the point of purchase with added health and price information. Phase 3 added a $33 \%$ price reduction. The duration of each phase was 3 weeks and phases were separated by 2 -week breaks. Primary outcomes were total pieces of fruit and number of meals sold daily.

Setting: A university cafeteria in Lima, Peru.

Subjects: Approximately 150 people, students and non-student adults, who purchased food daily. Twelve students participated in post-intervention interviews. Results: Fruit purchasing doubled from Phase 1 to Phase $3(P<0.01)$ and remained significant after adjusting for the number of meals sold daily $(P<0.05)$. There was no evidence of a difference in fruit sold between the other phases. Females purchased $100 \%$ of the fruit in Phase 1, 82\% in Phase 2 and $67 \%$ in Phase 3 $(P<0.01)$. Males increased their purchasing significantly between Phase 1 and 3 $(P<0.01)$. Non-student adults purchased more fruit with each phase $(P<0.05)$ whereas students did not. Qualitatively, the most common reason for not purchasing fruit was a marked preference to buy unhealthy snack foods.

Conclusions: Promoting fruit consumption by product placement close to the point of purchase, adding health information and price reduction had a positive effect on fruit purchasing in a university cafeteria, especially in males and nonstudent adults.
\end{abstract}

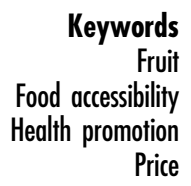

Fruit and vegetable intake has been shown to prevent the onset of a number of chronic diseases, such as $\mathrm{CVD}^{(1,2)}$, diabetes $^{(3)}$ and cancer $^{(4)}$, as well as other CVD risk factors $^{(1,5)}$. The promotion of fruit consumption has been widely used in research interventions ${ }^{(6)}$ and governmentinitiated school-based programmes ${ }^{(7)}$ as part of a balanced healthy diet and to prevent the onset of these diseases.

The WHO recommends the consumption of $400 \mathrm{~g}$ of fruit and vegetables each day ${ }^{(8)}$. This advice has been translated into ' 5 servings per day, 7 days a week' campaigns in many countries, which has been shown to be a better measure of intake than portion size ${ }^{(9)}$. However, limited individuallevel data exist about consumption of fruits and vegetables in Latin America.

One study of Andean adults in Peru showed that $34.5 \%$ had low fruit intake and $33.3 \%$ had low vegetable intake $^{(10)}$, where low intake was defined as consumption of fruits or fresh vegetables on less than $3 \mathrm{~d}$ /week. A study in Brazil noted that less than half of the participants reported adequate fruit and vegetable intake $(<5$ servings/d), with male gender, youth and lower educational attainment predicting inadequate intake ${ }^{(11)}$. Outside Latin America, various individual and environmental factors have been shown to contribute to low fruit and vegetable intake, including low socio-economic status ${ }^{(12)}$, environmental factors such as increased cost and low availability ${ }^{(13)}$, taste ${ }^{(14,15)}$, improved marketing strategies of unhealthy foods, the surge of the rapid increase in fast-food culture ${ }^{(8,16)}$, and demographic factors such as younger age and male sex ${ }^{(11)}$.

Interventions that aim to modify healthy food intake through change in the purchasing environment, specifically those related to accessibility, provision of nutritional information at the point of purchase and price reductions, have been effective in increasing healthy food consumption ${ }^{(17-19)}$. 
Table 1 The design of the quasi-experimental study with one baseline and two intervention phases

\begin{tabular}{|c|c|c|c|}
\hline Variable & Phase 1-Baseline & Phase 2-Intervention I & Phase 3-Intervention II \\
\hline Type of fruit & Apples, pears and mandarins & Apples, pears and mandarins & Apples, pears and mandarins \\
\hline $\begin{array}{l}\text { Position in cafeteria } \\
\text { lunch line }\end{array}$ & $\begin{array}{l}\text { In a refrigerated display cabinet } \\
>3 \mathrm{~m} \text { from the point of purchase }\end{array}$ & Next to the point of purchase & Next to the point of purchase \\
\hline $\begin{array}{l}\text { Additional information } \\
\text { provided }\end{array}$ & None & $\begin{array}{l}\text { Information about price and the } \\
\text { health benefits of fruit consumption }\end{array}$ & $\begin{array}{l}\text { Information about price and the } \\
\text { health benefits of fruit consumption }\end{array}$ \\
\hline Price & PEN 1.50 (\$US 0.57) & PEN 1.50 (\$US 0.57) & PEN 1.00 (\$US 0.38) \\
\hline $\begin{array}{l}\text { Daily hours on sale } \\
\text { (Monday to Friday) }\end{array}$ & $8: 00 \mathrm{am}-5: 00 \mathrm{pm}$ & $8: 00$ am-5:00 pm & $8: 00$ am-5:00 pm \\
\hline Duration of phase & 3 weeks & 3 weeks & 3 weeks \\
\hline
\end{tabular}

Strong evidence exists for the effectiveness of certain tools based on the use of the marketing mix ${ }^{(20)}$, also known as the 4 P's: product, promotion, placement and price ${ }^{(21)}$. This approach promotes healthy lifestyle habits through health information ${ }^{(22,23)}$, increased availability of healthy foods ${ }^{(18,24,25)}$ and promotions that lower the price of healthy foods ${ }^{(26-28)}$.

The promotion of foods, through adequately and strategically placed nutritional information in posters, brochures, etc., reminds the consumer of the health benefits of fruit. A statement from the American Heart Association on population approaches to improve diet recommends the use of subsidy strategies to lower prices of healthy foods as an effective intervention with strong supportive evidence ${ }^{(22)}$. However, there is a scarcity of studies on interventions that change environmental and pricing factors despite the success of point-of-purchase information having been widely documented $^{(17)}$. In the USA, a recent cluster randomized controlled trial of in-store marketing strategies to promote sales of healthier items in low-income, high-minority neighbourhoods showed that straightforward placement strategies can significantly enhance the sales of healthier items in several food and beverage categories, specifically milk, water and some types of frozen meals ${ }^{(19)}$.

The aim of the present study was to determine the effect of improving visibility, providing health information and lowering the price of fruit on fruit purchasing in a university cafeteria in Lima, Peru. We also explored the perceptions of the cafeteria's clients about the changes in marketing strategy and their fruit purchasing preferences through focused interviews.

\section{Experimental methods}

\section{Design}

The present study was a quasi-experimental pilot study, in which individuals were exposed to three different consecutive fruit marketing strategies. This was an uncontrolled trial introduced into the cafeteria's daily practice without randomization at the individual level. The factors that were under the control of the investigators were the marketing strategy of fruit, including fruit position in the cafeteria, information available about the health benefits of fruit and the price of the fruit.

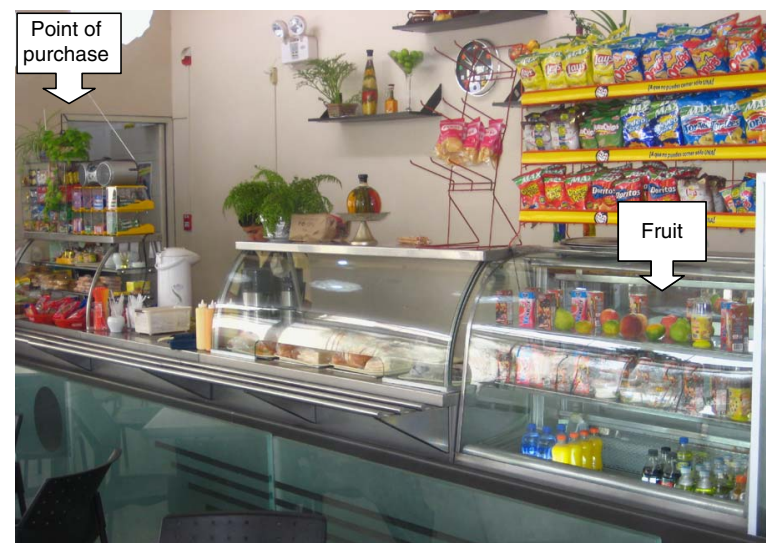

Fig. 1 (colour online) Fruit location in Phase 1

\section{Experimental phases}

There were three phases of this stepped intervention. Each 3 -week phase was separated by a 2 -week break due to holidays and other events that could affect the usual number of clients and items sold each day (Table 1). The first phase served as the baseline control phase, in which whole fresh fruit was presented in a display case at a site distant from the point of purchase ( $>3 \mathrm{~m}$ from the register) in its usual position (Fig. 1). The second phase consisted of repositioning the fruit into a covered container clearly displayed next to the point of purchase (Figs 2 and 3(a)). The cover of the container had a sign stating 'Consuming five fruits and vegetables per day prevents many illnesses World Health Organization' in the local language (Spanish) that also included the price per item of fruit. Two posters (A4 size) with this message and price were also placed at the entrance of the cafeteria and on the wall next to the point of purchase. The third and final phase maintained the intervention introduced in Phase 2 but lowered the price by $33 \%$ per item of fruit, from local price PEN 1.50 (\$US 0.57) to PEN 1.00 (\$US 0.38; Figs 2 and 3(b)). The research team covered the costs of buying fresh fruit during the study so that the cafeteria manager was not financially affected by the changes in price.

\section{Population and setting}

The study was conducted in a university cafeteria that caters to approximately 200 students each day, the 
majority of whom were young adults who had graduated from high school and were enrolled full time at the university. In addition, there were approximately eighty administrative staff and faculty members, hereafter referred to as 'non-student adults'. These data were provided by the university campus administration.

\section{Procedures and data collection}

Data collected by the salesperson through daily logs were: (i) the number of pieces of fruit sold each day; (ii) the number of full meals sold; and (iii) visible information about each fruit consumer such as the purchaser's sex and age group (students $v$. non-student adults).

To avoid major variations in the flux of customers across phases, the daily hours in which fruit was sold in the cafeteria were strictly controlled. Coordination with the cafeteria manager and staff during all phases of the experiment focused on the following issues: (i) not revealing to customers that fruit consumption was being recorded for a study; (ii) complying with the hours of fruit sales; (iii) the location of the fruit; (iv) logistical issues

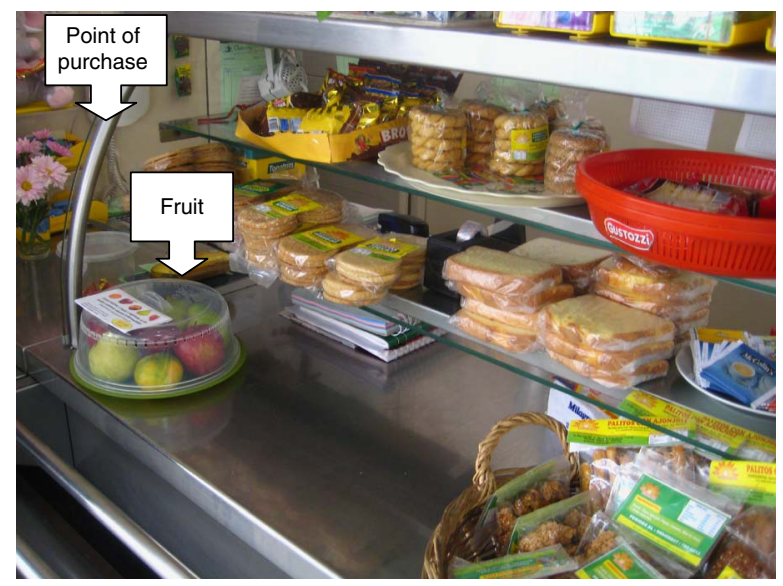

Fig. 2 (colour online) Fruit location near the point of purchase in Phase 2 and Phase 3

(a)

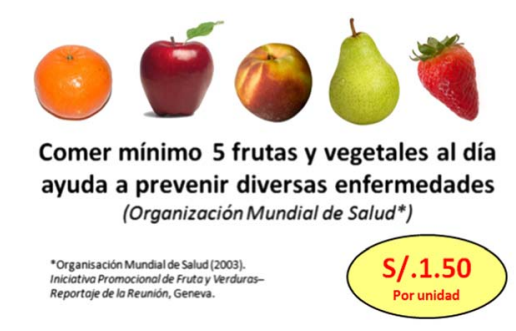

(b)

\section{Analysis}

The primary outcome variables in the study were: (i) daily pieces of whole fruit purchased; (ii) daily number of full meals sold, hereafter referred to as 'meals', a proxy measure of the daily number of cafeteria users; and (iii) the fruit ratio, defined as the ratio between the total pieces of fruit purchased and the total number of meals sold in the same

day. There were $14-15 \mathrm{~d}$ of observation for each phase.

including fruit purchase, quality assurance and freshness; (v) recording of data; and (vi) weekly data transfer to the research team. Fruit provided to the cafeteria was of optimal appearance and quality.

There was no enrolment in the study, but the cafeteria manager estimated that there were approximately 150 customers per day during the entire study, all of whom were exposed to changes in marketing strategies in Phases

After the end of Phase 3, twelve semi-structured interviews were conducted with students who use the cafeteria. Two investigators asked them to participate in the study after the classes. The sample of invited students was purpoof whom must have purchased fruit in the cafeteria at least once during the 9 weeks of the study. The main aim of the interviews was to obtain qualitative data regarding perceptions of the marketing strategies of fruit. Information requested included demographic questions, whether or not the student purchased fruit in the cafeteria and why, whether or not the student knew that fruit was available for sale, as well as if the student noticed the reduction in fruit price. We also explored the main reasons for not purchasing fruit. The interviews lasted approximately $20 \mathrm{~min}$ and were conducted by two researchers after informed consent was or were under 18 years of age were excluded from this qualitative phase but not from the open experiment.

\section{Qualitative interviews}

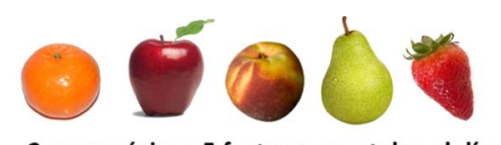

Comer mínimo 5 frutas y vegetales al día ayuda a prevenir diversas enfermedades (Organización Mundial de Salud*)

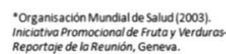

\section{$\mathrm{S} / .1 .00$}

Fig. 3 (colour online) Message in the covered container and on posters in (a) Phase 2 and (b) Phase 3 


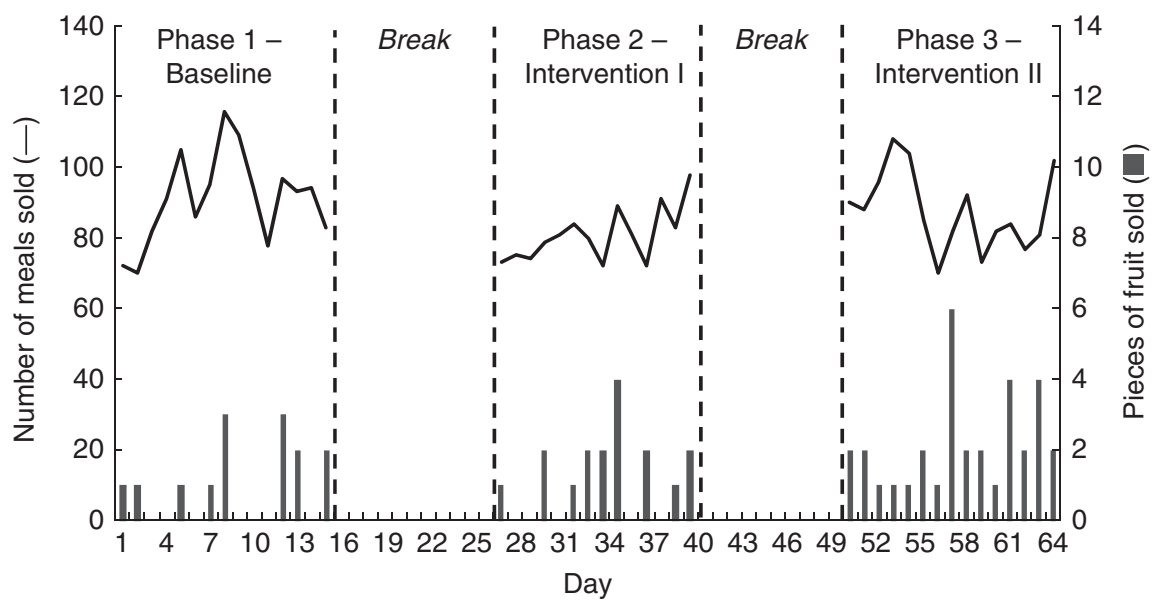

Fig. 4 Total number of meals sold daily (-) and total pieces of whole fruit sold daily $(\square)$ over time during the three-phase stepped intervention on fruit purchasing in a university cafeteria, Lima, Peru

Table 2 Descriptive statistics of outcome variables in the three-phase stepped intervention on fruit purchasing in a university cafeteria, Lima, Peru

\begin{tabular}{|c|c|c|c|c|c|c|c|}
\hline & Days & Mean & SD & Median & Minimum & Maximum & Kruskal-Wallis $\chi^{2}(P$ value $)$ \\
\hline \multicolumn{8}{|c|}{ Total pieces of fruit sold daily } \\
\hline Phase 1 & 15 & 0.93 & $1 \cdot 10$ & 1 & 0 & 3 & \multirow{3}{*}{$\begin{array}{c}7.537 \\
(P=0.023)\end{array}$} \\
\hline Phase 2 & 14 & 1.21 & $1 \cdot 19$ & 1 & 0 & 4 & \\
\hline Phase 3 & 15 & $2 \cdot 20$ & 1.42 & 2 & 1 & 6 & \\
\hline \multicolumn{8}{|c|}{ Number of meals sold daily } \\
\hline Phase 1 & 15 & 91.00 & $12 \cdot 98$ & 93 & 70 & 116 & \multirow{3}{*}{$\begin{array}{c}5.791 \\
(P=0.055)\end{array}$} \\
\hline Phase 2 & 14 & $80 \cdot 86$ & 7.76 & 81 & 72 & 98 & \\
\hline Phase 3 & 15 & $87 \cdot 60$ & $11 \cdot 18$ & 85 & 70 & 108 & \\
\hline \multicolumn{8}{|c|}{ Fruit ratio: total pieces of fruit sold/number of meals sold } \\
\hline Phase 1 & 15 & 0.010 & 0.011 & 0.010 & 0.000 & 0.031 & \multirow{3}{*}{$\begin{array}{c}6.542 \\
(P=0.038)\end{array}$} \\
\hline Phase 2 & 14 & 0.015 & 0.014 & 0.013 & 0.000 & 0.045 & \\
\hline Phase 3 & 15 & 0.026 & 0.018 & 0.022 & 0.009 & 0.073 & \\
\hline
\end{tabular}

Analysis of the primary outcome variables was done using the non-parametric Kruskal-Wallis test for comparing pieces of fruit sold and fruit ratio across the three phases. Pre-defined subgroup analyses were conducted by age and sex groups. A $P$ value of $<0.05$ was considered statistically significant. We used the statistical software package STATA 12.0 for Windows for all statistical analyses. The qualitative interviews were reviewed by three different investigators and codification was developed according to the major themes identified, such as awareness of the marketing strategies and reasons for not purchasing fruit.

\section{Results}

Figure 4 shows daily customer counts (total meals sold) and pieces of whole fruit sold during the 12-week study period, which included a total of $44 \mathrm{~d}$ of study and $21 \mathrm{~d}$ of break.

The average number of meals sold was largely stable over the study period (Table 2) with a total of 91 (SD 12.98), 80 (SD 7.75) and 87 (SD 11.18) meals sold daily in each phase, respectively. Only the total number of meals sold in Phase 1 was significantly higher than in Phase $2(P<0.05)$. The minimum and maximum number of daily meals ranged from 70 to 116 .

Over the duration of the three-phase study, sixty-four pieces of fruit (daily mean 1.45 (SD 1.34)) were sold. A total of fourteen pieces of fruit (daily mean 0.93 (SD 1.10)) were sold in Phase 1, seventeen pieces of fruit (daily mean 1.21 (SD 1.19)) in Phase 2 and thirty-three pieces of fruit (daily mean 2.20 (SD 1.42)) in Phase 3 (see Table 2 and Fig. 4). Fruit purchasing doubled from Phase 1 to Phase 3 $(P<0 \cdot 01)$, but there was no evidence of a difference in total fruit sold between the other phases (Table 3). When adjusting for the total number of meals sold each day, the increased fruit sold remained significant between Phases 1 and $3(P<0 \cdot 01$; Table 3$)$.

Females purchased more fruit overall. Of the fruit purchased in Phase 1, $100 \%$ was purchased by females (Fig. 5). However, by Phase 3, females only purchased $67 \%$ of the total fruit $(P<0.01)$ because males increased their purchase of fruit significantly after the introduction of improved visibility, health information and price reduction strategies: specifically, males purchased no fruit in 
Table 3 Results of the Kruskal-Wallis tests comparing each pair of phases in the three-phase stepped intervention on fruit purchasing in a university cafeteria, Lima, Peru

\begin{tabular}{lccc}
\hline & Phase 1 to Phase 2 & Phase 2 to Phase 3 & Phase 1 to Phase 3 \\
\hline Total fruits sold & & & 6.969 \\
$\quad$ Kruskal-Wallis $X^{2}$ & 0.444 & 3.721 & 0.008 \\
$P$ value & 0.505 & 0.054 & 0.760 \\
$\quad$ Total meals sold & & 3.208 & 0.383 \\
$\quad$ Kruskal-Wallis $X^{2}$ & 4.771 & 0.073 & 6.698 \\
$\quad P$ value & 0.029 & 0.085 & 0.009 \\
$\begin{array}{l}\text { Fruit ratio: total fruits sold/meals sold } \\
\quad \text { Kruskal-Wallis } X^{2}\end{array}$ & 0.779 & 0.149 & \\
$P$ value & 0.377 & & \\
\hline
\end{tabular}

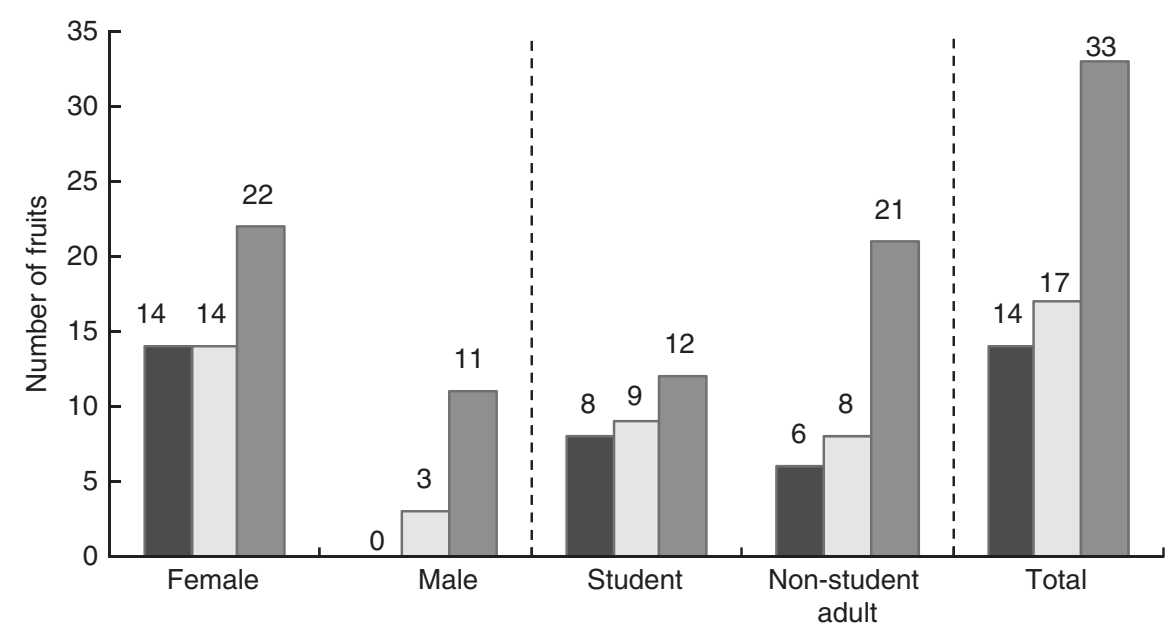

Fig. 5 Total fruit purchased overall, by sex and by age group in each experimental phase ( $\square$, Phase 1; $\square$, Phase 2; $\square$, Phase 3) during the three-phase stepped intervention on fruit purchasing in a university cafeteria, Lima, Peru

Phase 1, but purchased eleven pieces of fruit in Phase 3 $(P<0 \cdot 01)$.

Non-student adults increased their fruit purchasing when exposed to each of the different experimental phases $(P<0.05$ for Phase 1 to 2 , for Phase 2 to 3 and for Phase 1 to 3 ), but this increase was not observed among students. Between Phases 1 and 3, non-student adult females doubled their fruit purchasing, while non-student adult men tripled their purchasing. However, male students were the group with the lowest fruit consumption: only two male students purchased fruit during the study, both in Phase 3. Female students maintained a constant level of purchasing throughout the study (eight, nine and ten pieces of fruit in Phases 1, 2 and 3, respectively).

Of the twelve students interviewed, only one did not notice that fruit was available for sale in the cafeteria. Of the eleven students who noticed the fruit visibility experiment, nearly half noticed that the fruit price had changed in Phase 3, and two in twelve students identified price as a barrier to purchase. One of the most common reasons for not purchasing fruit in the cafeteria was a marked preference to use extra cash to buy cookies, pastry items and other unhealthy snack foods. Other reasons included preferences for unavailable fruit types, preferences regarding the way in which fruit was displayed and prepared, suspicions regarding the freshness of the fruit provided in the cafeteria, and bringing fruit from home to eat.

\section{Discussion}

\section{Main findings}

The present quasi-experimental study demonstrated that fruit purchasing increased with a simple intervention: improving visibility with fruit position near the point of purchase, adding information on health and price near the point of purchase, and reducing the price. Our results found that this combined strategy doubled fruit purchasing among cafeteria users compared with a baseline period without the intervention. In the study, females purchased more fruit overall, although men were more sensitive to the changes in marketing strategy, increasing their purchasing dramatically between each phase. Students did not respond to changes in marketing strategies, reflecting the challenges in promoting fruit purchasing among young adults.

The study also found low baseline levels of fruit sales in the cafeteria in general. This result should not be 
interpreted as an indication of low fruit consumption among the cafeteria users, because we did not explore their detailed patterns of fruit intake. However, in another Peruvian setting, there is evidence from a populationbased survey that at least one-third of the adult population in an urban city consumed fruits on less than $3 \mathrm{~d} /$ week $^{(10)}$. In this larger context, more ambitious strategies are needed to promote fruit consumption in Peru.

\section{Other studies in the field}

There is a scarcity of studies with interventions utilizing promotional strategies that incorporate both changes in environmental factors and pricing to promote healthy food consumption in cafeterias. Being an important day-to-day environmental interaction prone to the introduction of healthy, or unhealthy, food patterns, these deserve to be studied. Two studies, one developed by Jeffery et $a l .^{(29)}$ in a university cafeteria and another by French ${ }^{(26)}$ in two high-school cafeterias, found that reducing the price of fruit by $50 \%$ increased the purchasing of fruit between three- and fourfold. Those studies included a final phase which consisted of a return to baseline conditions, showing that fruit purchase then reverted to its original lower level. Our study was more conservative in price reduction (33\%) compared with the previous studies and the finding was also more moderate, with only a twofold increase in purchasing. Our study population was similar to that of French's study ${ }^{(26)}$, given that employees and young students were the main users of the cafeterias.

The effectiveness of monetary subsidies in promoting healthy food consumption was demonstrated in a review of twenty studies from developed countries (USA, Canada, Europe, New Zealand and South Africa) ${ }^{(1)}$. Our study suggests that monetary subsidy in the form of a discount in the price of fruit is a valid strategy in a Latin American middle-income setting. However, our study population, in a university, is in a better economic situation than the majority of the Peruvian population. Also, the intervention did not have a uniform effect on students and non-student adults, nor on men and women.

Other studies have explored the positive effect of financial incentives on healthy food purchasing, but these are not comparable to our study because they implemented the intervention using vending machines or in grocery stores and they promoted different types of healthy food items, such as low-fat snacks ${ }^{(1)}$.

Our study explored not only the price effect, but the effect of providing a health message with better visibility of fruit near the point of purchase as well. Interventions using pointof-purchase promotion have demonstrated success as marketing strategy ${ }^{(14,17)}$. In contrast, the use of health messages shows inconclusive results in terms of effectiveness ${ }^{(28,30,31)}$. In the unsuccessful interventions with university students, one potential explanation is that nutrition labelling is less eye-catching and does not advertise as well the taste, cost, convenience and energy value of fruit compared with unhealthy options ${ }^{(14,28)}$.
Our results support the argument that interventions to make healthier foods more economically attractive may be more effective than nutrition or health messages alone ${ }^{(28)}$.

The low fruit consumption among the young adult population, and their poor response to the intervention, guided the decision to focus our qualitative study on the student group. We identified variables that were important in this subgroup, including fruit preference, fruit preparation and non-fruit snacks with less nutritional value. Awareness of the nutritional value of fruit over other sweet snacks was identified; however, the less nutritional snacks were frequently cited as a more popular choice, potentially explaining the poor response to the health promotion message of fruit. Failure of the cost reduction strategy to impact this group was harder to explain. One participant explained that the price of fruit would have to be the same as that at the local market for her to consider buying fruit at the cafeteria.

Our qualitative study identified a range of factors that contribute to the low fruit purchasing among students at the university cafeteria, as well as factors that may explain the resistance to these interventions. However, most of these students live with their parents and the easy access to fruit in the family home may help explain this difference. Further study could help determine actual fruit intake in this age group. The challenge for policy makers attempting to increase fruit intake in this group is to design an intervention that overcomes these barriers.

\section{Limitations of the study}

In the present study we were not able to differentiate the isolated effects of placement, promotion or price. Yet, this trade-off in the design was made to align our interventions to real scenarios, in which a package of progressive changes is implemented as per established marketing strategies around product, promotion, placement and price.

The study was limited in that only pre-post comparisons were conducted. Thus, results may have been influenced by temporal changes, such as a process of desensitization to fruit sales. In order to tackle this problem, we designed the study taking into account variables that may have threatened its validity. To diminish these weaknesses, we implemented the experiment during weeks with few or no days of holiday or conferences inside the university campus that may have altered the number of customers in the cafeteria. We also registered the number of meals sold each day to control for any other relevant changes that might have introduced higher volumes of meals sold in the cafeteria. Our results did not show any major fluctuations in total sales across phases.

Our study did not include a return to baseline scenario after the experimental phases; therefore, we could not analyse if the positive effect of fruit purchasing was sustained over time or not. However, we know from previous studies that after price reduction is suppressed, fruit sales return to their original level ${ }^{(26,29)}$, confirming that the 
increase in fruit purchases is strongly related to the introduction of a financial incentive, and this may be true for the health message and point-of-purchase interventions, too.

Ideally, electronic records could have informed us if there was any substitution effect when fruit purchases increased, such as a reduction in overall purchasing of unhealthy foods. However, we were not able to capture this in our study as the cafeteria did not have an electronic system. The substitution effect is an important indicator that merits attention when designing future studies. Ni Mhurchu et al. ${ }^{(32)}$ provide an example of a monitoring framework to use when designing future studies.

Finally, our study was implemented in a cafeteria of a university located in a population of middle-to-high socioeconomic level with higher educational attainment. This population is not representative of the entire population of a developing country like Peru; yet the experiment conducted was worth exploring in this setting as it enabled a favourable assessment of the effects of changes in fruit's visibility and price reduction across sex and age groups.

\section{Strengths of the study and further research}

The present study is the first one in Peru and probably one of the first in Latin America to explore how quick, low-cost, simple interventions using combined marketing tools such as promotional messages, product placement and changes in price of healthy items can make a big difference in consumer purchasing and subsequent health behaviours. According to Epstein et al. ${ }^{(31)}$, this kind of experimental research is still in an early stage. Therefore, more of these approaches are needed, especially in developing countries.

The fact that our experiment was conducted under pragmatic day-to-day circumstances, and not under laboratory conditions, provides us with an element of external validity, as Epstein et al. ${ }^{(31)}$ point out, while being aware of its limitations in generalizability. Students and staff from the university campus face a real situation in which any cafeteria customer can shop at convenience stores outside the university, and can choose from among healthy and unhealthy food items, such as snacks (chips, candy, crackers), beverages (water, soft drinks, juice), desserts, etc.

Other strengths of our study include: (i) the recording of two pieces of basic personal information, sex and a proxy of age; (ii) an affordable price of fruit (less than \$US 0.50) that removed disincentives related to cost; and (iii) the use of a health message near the point of purchase based on the '5-a-day' recommendation by the WHO, which has also been promoted by Glanz and Hoelscher ${ }^{(17)}$.

Multi-site studies in real-world scenarios are needed to provide more information on the external validity of the results.

\section{Conclusion}

The current pilot study suggests that promoting fruit through a combination of product placement close to the point of purchase, added health information and lower price has a large positive effect on fruit purchasing, especially among non-student adults and males in a university cafeteria. Students were more resistant to behavioural change than non-student adults to the interventions that promoted fruit purchasing.

\section{Acknowledgements}

Acknowledgements: The authors' special appreciation and thanks go to Ana María Flores, Giuliana Vargas and Stephany Curipaco, among other members of the cafeteria's staff, for providing valuable support with authorization, sales data registration and logistics. Francisco Diez Canseco, Antonio Bernabé and Germán Málaga contributed with relevant suggestions. Financial support: M.K.C., J.J.M. and the CRONICAS Center of Excellence in Chronic Diseases at Universidad Peruana Cayetano Heredia were funded by the National Heart, Lung, and Blood Institute (NHLBI), National Institutes of Health (NIH), US Department of Health and Human Services (contract number HHSN268200900033C). C.P.B. was supported by the NIH and Fogarty International Center through the International Clinical Research Fellows Program at Vanderbilt University (grant number R24 TW007988). The funders had no role in the design, analysis or writing of this article. Conflict of interest: None. Authorship: M.K.C., T.D.P. and J.J.M. conceived and designed the experiments; M.K.C. and T.D.P. performed the experiments; M.K.C. and C.P.B. analysed the data; M.K.C., T.D.P. and C.P.B. wrote the manuscript; all authors gave final approval of the version submitted for publication. Ethics of buman subject participation: This study was conducted according to the guidelines laid down in the Declaration of Helsinki and all procedures involving human subjects/patients were approved by the Hospital Nacional Cayetano Heredia, in Lima, Peru. For the intervention, we did not seek the consent of individuals because no identifying individual data were collected (only age group and sex) and the authors felt there was negligible risk involved for the participants; furthermore, knowledge of the experiment would have been in conflict with the study design, which uses a before-after comparison instead of a control group. Verbal informed consent was obtained from all participants in the qualitative study.

\section{References}

1. Hartley L, Igbinedion E, Holmes J et al. (2013) Increased consumption of fruit and vegetables for the primary prevention of cardiovascular diseases. Cochrane Database Syst Rev 6, CD009874.

2. Ness AR \& Powles JW (1997) Fruit and vegetables, and cardiovascular disease: a review. Int J Epidemiol 26, $1-13$.

3. Bazzano LA (2005) Dietary Intake of Fruit and Vegetables and Risk of Diabetes Mellitus and Cardiovascular Diseases. Background Paper for the Joint FAO/WHO Workshop on 
Fruit and Vegetables for Health, 1-3 September 2004, Kobe, Japan. Geneva: WHO.

4. Riboli E \& Norat T (2003) Epidemiologic evidence of the protective effect of fruit and vegetables on cancer risk. $A m J$ Clin Nutr 78, Suppl. 3, 559S-569S.

5. Rees K, Dyakova M, Wilson N et al. (2013) Dietary advice for reducing cardiovascular risk. Cochrane Database Syst Rev 12, CD002128.

6. Pomerleau J, Lock K, Knai C et al. (2005) Effectiveness of Interventions and Programmes Promoting Fruit and Vegetables Intake. Background Paper for the Joint FAO/ WHO Workshop on Fruit and Vegetables for Health, 1-3 September 2004, Kobe, Japan. Geneva: WHO.

7. Bere E, Hilsen M \& Klepp KI (2010) Effect of the nationwide free school fruit scheme in Norway. Br J Nutr 104, 589-594.

8. World Health Organization (2005) Fruit and Vegetables for Health. Report of a Joint FAO/WHO Workshop on Fruit and Vegetables for Health, 1-3 September 2004, Kobe, Japan. Geneva: WHO.

9. Ashfield-Watt PA, Welch AA, Day NE et al. (2004) Is 'five-aday' an effective way of increasing fruit and vegetable intakes? Public Health Nutr 7, 257-261.

10. Medina-Lezama J, Morey-Vargas OL, Zea-Diaz $\mathrm{H}$ et al. (2008) Prevalence of lifestyle-related cardiovascular risk factors in Peru: the PREVENCION study. Rev Panam Salud Publica 24, 169-179.

11. Figueiredo IC, Jaime PC \& Monteiro CA (2008) Factors associated with fruit and vegetable intake among adults of the city of Sao Paulo, Southeastern Brazil. Rev Saude Publica 42, 777-785.

12. Darmon N \& Drewnowski A (2008) Does social class predict diet quality? Am J Clin Nutr 87, 1107-1117.

13. Pollard J, Kirk SF \& Cade JE (2002) Factors affecting food choice in relation to fruit and vegetable intake: a review. Nutr Res Rev 15, 373-387.

14. Buscher LA, Martin KA \& Crocker S (2001) Point-ofpurchase messages framed in terms of cost, convenience, taste, and energy improve healthful snack selection in a college foodservice setting. J Am Diet Assoc 101, 909-913.

15. Shannon C, Story M, Fulkerson JA et al. (2002) Factors in the school cafeteria influencing food choices by high school students. J Sch Health 72, 229-234.

16. Powell LM, Han E \& Chaloupka FJ (2010) Economic contextual factors, food consumption, and obesity among U.S. adolescents. J Nutr 140, 1175-1180.

17. Glanz K \& Hoelscher D (2004) Increasing fruit and vegetable intake by changing environments, policy and pricing: restaurant-based research, strategies, and recommendations. Prev Med 39, Suppl. 2, S88-S93.
18. Van Kleef E, Otten K \& van Trijp HC (2012) Healthy snacks at the checkout counter: a lab and field study on the impact of shelf arrangement and assortment structure on consumer choices. BMC Public Health 12, 1072

19. Foster GD, Karpyn A, Wojtanowski AC et al. (2014) Placement and promotion strategies to increase sales of healthier products in supermarkets in low-income, ethnically diverse neighborhoods: a randomized controlled trial. Am J Clin Nutr 99, 1359-1368.

20. Point of Purchase Advertising Institute (1978) POPAI/ DuPont Consumer Buying Habits Study. Special Report. New York: Point-of-Purchase Advertising Institute.

21. Glanz K, Bader MD \& Iyer S (2012) Retail grocery store marketing strategies and obesity: an integrative review. $\mathrm{AmJ}$ Prev Med 42, 503-512.

22. Mozaffarian D, Afshin A, Benowitz NL et al. (2012) Population approaches to improve diet, physical activity, and smoking habits: a scientific statement from the American Heart Association. Circulation 126, 1514-1563.

23. Michels KB, Bloom BR, Riccardi P et al. (2008) A study of the importance of education and cost incentives on individual food choices at the Harvard School of Public Health cafeteria. J Am Coll Nutr 27, 6-11.

24. American Dietetic Association (1986) Worksite Nutrition: A Decision Maker's Guide. Chicago, IL: The American Dietetic Association.

25. Farnon CU (1981) Let's offer employees a healthier diet. J Occup Med 23, 273-276.

26. French SA (2003) Pricing effects on food choices. J Nutr 133, issue 3, 841S-843S.

27. Jaeger SR, Harker R, Triggs CM et al. (2011) Determining consumer purchase intentions: the importance of dry matter, size, and price of kiwifruit. J Food Sci 76, issue 3, S177-S184.

28. Horgen KB \& Brownell KD (2002) Comparison of price change and health message interventions in promoting healthy food choices. Health Psychol 21, 505-512.

29. Jeffery RW, French SA, Raether C et al. (1994) An environmental intervention to increase fruit and salad purchases in a cafeteria. Prev Med 23, 788-792.

30. Anderson JV, Bybee DI, Brown RM et al. (2001) 5 a day fruit and vegetable intervention improves consumption in a low income population. J Am Diet Assoc 101, 195-202.

31. Epstein LH, Jankowiak N, Nederkoorn C et al. (2012) Experimental research on the relation between food price changes and food-purchasing patterns: a targeted review. Am J Clin Nutr 95, 789-809.

32. Ni Mhurchu C, Vandevijvere S, Waterlander W et al. (2013) Monitoring the availability of healthy and unhealthy foods and non-alcoholic beverages in community and consumer retail food environments globally. Obes Rev 14, Suppl. 1, 108-119. 